\section{Case Reports in Neurology}

Case Rep Neurol 2021;13:78-83

DOI: $10.1159 / 000512323$

Published online: February 8, 2021
(C) 2021 The Author(s)

Published by S. Karger AG, Basel www.karger.com/crn

This article is licensed under the Creative Commons Attribution-NonCommercial 4.0 International License (CC BY-NC) (http://www.karger.com/Services/OpenAccessLicense). Usage and distribution for commercial purposes requires written permission.

\title{
Two Cases of Probable Neuro- Behçet's Disease with Longitudinally Extensive Transverse Myelitis
}

\author{
Shunya Fujiwara ${ }^{a}$ Yasuhiro Manabe ${ }^{a}$ Yumiko Nakano ${ }^{a}$ Yoshio Omote $^{a}$ \\ Taijun Yunoki $^{\mathrm{a}}$ Syoichiro Kono ${ }^{\mathrm{a}}$ Hisashi Narai $^{\mathrm{a}} \mathrm{Koji}^{\mathrm{Abe}}{ }^{\mathrm{b}}$ \\ aDepartment of Neurology, National Hospital Organization Okayama Medical Center, \\ Okayama, Japan; ${ }^{b}$ Department of Neurology, Graduate School of Medicine, Dentistry and \\ Pharmaceutical Sciences, Okayama University, Okayama, Japan
}

\section{Keywords}

Neuro-Behçet's disease $\cdot$ Long spinal cord lesion · Myelitis

\begin{abstract}
We report 2 cases of probable neuro-Behçet's disease (NBD) with longitudinally extensive transverse myelitis (LETM). In both cases, the patients presented paraplegia, as well as sensory, bladder, and rectal disturbances. Magnetic resonance imaging (MRI) of patient 1 showed continuous high signal intensity extending from the midbrain to the entire spinal cord in the central part of the cord on T2-weighted imaging (T2WI). Spinal MRI of patient 2 revealed high signal intensity extending from Th2 to Th10 in the central part of the cord on T2WI. Both patients received high-dose methylprednisolone. A continuous lesion from the midbrain to the entire spinal cord as in patient 1 has not been previously reported. Patient 2 dramatically improved by infliximab therapy. The present cases suggest that NBD should be considered as a differential diagnosis in patients with LETM.




\section{Case Reports in Neurology}

Case Rep Neurol 2021;13:78-83

\begin{tabular}{l|l}
\hline DOI: 10.1159/000512323 & ๑ 2021 The Author(s). Published by S. Karger AG, Basel \\
\hline
\end{tabular} www.karger.com/crn

Fujiwara et al.: Probable NBD with LETM

\section{Introduction}

Behçet's disease (BD) is a chronic, relapsing, multisystem, vascular inflammatory disease $[1,2]$. The neurological form, neuro-BD (NBD), usually affects the central nervous system, specifically the brainstem and diencephalic regions [1-4]. However, spinal cord involvement in NBD is rare and has not been fully studied. We present 2 cases of probable NBD with longitudinally extensive transverse myelitis (LETM).

\section{Case Report}

Case 1

A 52-year-old woman was admitted for progressive gait disturbance and hypoesthesia in both lower limbs over 3 years. She had uveitis at the age of 49 years and noticed recurrent oral ulcers. She had no familial history of neurological disorders. General physical examination was normal. Neurological examination revealed muscle weakness of grade 4/5 affecting the lower limbs as well as hyporeflexia in both lower limbs. Babinski and Chaddock signs were negative. She had wide-based and poor tandem walking. The Romberg sign was positive. There was loss of position and vibration sense combined with hypesthesia below Th10. She had bladder and rectal disturbance. She had a negative pathergy test.

Findings from routine serum studies were normal. CSF (cerebrospinal fluid) analysis showed a cell count of $200 / \mathrm{mL}$ ( $90 \%$ mononuclear cells), a normal glucose level, an increased protein concentration of $278 \mathrm{mg} / \mathrm{dL}$, a normal myelin basic protein level, IgG (immunoglobulin G) and albumin ratios of 0.87 (normal range $<0.7$ ), and negative oligoclonal bands. Antinuclear antibody, ANCA (anti-neutrophil cytoplasmic antibody), ACE (angiotensin-converting enzyme), and anti-aquaporin-4 (anti-AQP4) antibody (cell-based assay) were negative, and antiviral antibodies showed an existing pattern of infection.

Chest CT (computed tomography) showed no abnormality. Spinal magnetic resonance imaging (MRI) demonstrated high signal intensity extending from the midbrain to L1 in the central part of the cord on T2-weighted imaging (T2WI) (Fig. 1a-d, arrowhead). Sagittal and axial contrast-enhanced T1WI showed surface enhancement of the lesions (Fig. 1e, f, arrowheads). Brain MRI showed high signal intensity extending from the midbrain to the medulla oblongata on T2WI. There were no abnormal lesions in the basal ganglia, subcortical white matter, or cerebral cortex.

Autoimmune encephalitis and myelitis being suspected, she received high-dose methylprednisolone $(1,000 \mathrm{mg} /$ day for 3 days, 3 courses $)$; however, no clinical improvement was obtained. After the treatment, the patient was human leukocyte antigen (HLA)-B51 positive. She was diagnosed with probable NBD and followed up with daily prednisolone (50 $\mathrm{mg}$ ) and weekly methotrexate $(7.5 \mathrm{mg})$. She got better and could walk with the assistance of a walking instrument. Repeat MRI showed marked regression of the brainstem and spinal lesions 35 days after admission (Fig. 1g, h). The patient was discharged 68 days after admission with daily prednisolone $(15 \mathrm{mg})$ and weekly methotrexate $(7.5 \mathrm{mg})$. She did not agree to infliximab therapy.

Case 2

A 44-year-old man was admitted for acute-onset gait disturbance over 6 days. He had no familial history of neurological disorders. General physical examination was normal.

\section{Karger'=}




\section{Case Reports in Neurology}

Case Rep Neurol 2021;13:78-83

\begin{tabular}{l|l}
\hline DOI: 10.1159/000512323 & $\odot 2021$ The Author(s). Published by S. Karger AG, Basel
\end{tabular} www.karger.com/crn

Fujiwara et al.: Probable NBD with LETM

Neurological examination revealed muscle weakness of grade $0 / 5$ affecting the lower limbs. Deep tendon reflexes showed hyperreflexia of the face and upper limbs. There was reduced superficial and deep sensation in the limbs. He had bladder and rectal disturbance. He had folliculitis and epididymitis in his clinical course. He had a negative pathergy test.

Findings from routine serum testing were normal. CSF analysis showed a cell count of $37 / \mathrm{mL}$ (100\% mononuclear cells), a normal glucose level, an increased protein concentration of $69 \mathrm{mg} / \mathrm{dL}$, an increased myelin basic protein level of $>2,000 \mathrm{pg} / \mathrm{mL}$, IgG and albumin ratios of 0.25 (normal range <0.7), and negative oligoclonal bands. Antinuclear antibody, ANCA, ACE, and anti-AQP4 antibody (cell-based assay) were negative, and antiviral antibodies showed an existing pattern of infection.

Chest CT and brain MRI showed no abnormality. Spinal MRI revealed high signal intensity extending from Th2 to Th10 in the central part of the cord on T2WI (Fig. 2a, b). The lesions showed no contrast enhancement. Autoimmune myelitis being suspected, he received highdose methylprednisolone $(1,000 \mathrm{mg} /$ day for 3 days, 2 courses). He tested positive for HLAA26 and HLA-B51. He was diagnosed with probable NBD and followed up with daily prednisolone (30 mg). Muscle strength of the upper limb improved slightly; however, he was bedridden and the paraplegia persisted. Repeat MRI showed marked regression of the thoracic lesions 29 days after onset (Fig. 2c, d). The patient was treated with infliximab $5 \mathrm{mg} / \mathrm{kg}$ at weeks 0,2 , and 6 , and every 8 weeks thereafter. He got better and could walk with the assistance of a walking instrument. He was discharged to another hospital for rehabilitation 78 days after onset with daily prednisolone $(10 \mathrm{mg})$. He independently walked 4 months after onset.

\section{Discussion}

We reported 2 cases of probable NBD with LETM. Differential diagnoses of LETM include a broad range of conditions such as autoimmune inflammatory disease, infectious disease, neoplastic disease, nutritional deficiency, and traumatic injury [5, 6]. LETM is a common finding in neuromyelitis optica. However, the two patients had negative anti-AQP4 antibody results. The clinical picture, including a blood test and imaging assessment, also eliminated a diagnosis of other autoimmune inflammatory disease, infectious disease, neoplastic disease, nutritional deficiency, and traumatic injury. Although BD is a well-defined disease with well-established criteria for its diagnosis, the same is not true for NBD [3,4]. Patient 1 had uveitis at the age of 49 years and noticed recurrent oral ulcers. Patient 2 had folliculitis and epididymitis in the clinical course. We diagnosed the two patients on the basis of the criteria proposed by the international consensus recommendation for NBD $[3,4]$. The prevalence of spinal cord involvement in NBD ranges from 2.5 to 30\% [7-10]. In the reported cases, the main site of involvement was the cervical and thoracic spinal cord with myelitis-like inflammatory lesions continuing for more than two segments and extending to the brainstem in some cases [7-10]. The MRI of patient 1 showed a continuous lesion extending from the midbrain to the entire spinal cord. Such an MRI finding has not been previously reported. The pathophysiology of a long cord lesion is not fully understood. Autopsy studies and biopsy specimens support our findings that the inflammatory-venous pathogenesis seen was NBD [1]. The spinal cord veins run longitudinally along the spinal cord surface. Small vessel obstructions due to vasculitis along the spinal veins induce stagnation and edema in the central gray matter longitudinally

\section{Karger'=}




\section{Case Reports in Neurology}

Case Rep Neurol 2021;13:78-83

DOI: $10.1159 / 000512323$

(c) 2021 The Author(s). Published by S. Karger AG, Basel www.karger.com/crn

Fujiwara et al.: Probable NBD with LETM

[7]. The area of contrast enhancement on MRI in patient 1 supported the inflammatory-venous pathogenesis.

Patient 2 failed to respond to a high dose of steroid treatment but showed a good response to infliximab. Serum TNF (tumor necrosis factor)- $\alpha$ is increased in active BD [11-14]. TNF- $\alpha$ antagonist therapy, such as with infliximab, has shown significant improvements in various manifestations of BD [11-14]. Patient 2 dramatically improved in spite of the poor prognosis associated with spinal cord involvement in NBD. Treatment with immunotherapy, such as infliximab, should be considered in NBD with spinal cord involvement even if a corticosteroid was ineffective. Although spinal cord involvement in NBD is rare, NBD should be considered as a differential diagnosis in cases with LETM, even in those without uveitis and orogenital ulceration.

\section{Statement of Ethics}

Written informed consent was obtained from the patients for publication of this case report and any accompanying images.

\section{Conflict of Interest Statement}

The authors state that they have no conflicts of interest.

\section{Funding Sources}

The authors have nothing to disclose.

\section{Author Contributions}

Shunya Fujiwara and Yasuhiro Manabe designed the case report and wrote the manuscript. Shunya Fujiwara, Yasuhiro Manabe, Yumiko Nakano, Taijun Yunoki, Syoichiro Kono, Yoshio Omote, and Hisashi Narai contributed to the diagnosis, physical examination, and testing of the patient. Koji Abe supervised this case report and clinical practice. All authors read and approved the final manuscript.

\section{References}

1 Koçer N, Islak C, Siva A, Saip S, Akman C, Kantarci O, et al. CNS involvement in neuro-Behçet syndrome: an MR study. AJNR Am J Neuroradiol. 1999 Jun-Jul;20(6):1015-24.

2 Yesilot N, Mutlu M, Gungor O, Baykal B, Serdaroglu P, Akman-Demir G. Clinical characteristics and course of spinal cord involvement in Behçet's disease. Eur J Neurol. 2007 Jul;14(7):729-37.

3 Kalra S, Silman A, Akman-Demir G, Bohlega S, Borhani-Haghighi A, Constantinescu CS, et al. Diagnosis and management of Neuro-Behçet's disease: international consensus recommendations. J Neurol. 2014 Sep;261(9):1662-76.

4 Uygunoglu U, Saip S, Siva A. Behçet's disease and Neuro-Behçet's syndrome. EMJ Neurol. 2018;6(1):77-85.

\section{Karger'=}




\section{Case Reports in Neurology}

\begin{tabular}{l|l}
\hline Case Rep Neurol 2021;13:78-83 \\
\hline DOI: 10.1159/000512323 & $\begin{array}{l}\text { @ 2021 The Author(s). Published by S. Karger AG, Basel } \\
\text { www.karger.com/crn }\end{array}$ \\
\hline
\end{tabular}

Fujiwara et al.: Probable NBD with LETM

5 Habek M, Adamec I, Pavliša G, Brinar VV. Diagnostic approach of patients with longitudinally extensive transverse myelitis. Acta Neurol Belg. 2012 Mar;112(1):39-43.

6 Cobo-Calvo Á, Alentorn A, Mañé Martínez MA, Bau L, Matas E, Bruna J, et al. Etiologic spectrum and prognosis of longitudinally extensive transverse myelopathies. Eur Neurol. 2014;72(1-2):86-94.

7 Fukae J, Noda K, Fujishima K, Takahashi T, Hattori N, Okuma Y. Subacute longitudinal myelitis associated with Behcet's disease. Intern Med. 2010;49(4):343-7.

8 Al Sawaf A, Berger JR. Longitudinally extensive transverse myelitis suspected for isolated Neuro-Behçet: a diagnostic conundrum. Mult Scler Relat Disord. 2015 Sep;4(5):395-9.

9 Coulter I, Huda S, Baborie A, Jacob A. Longitudinally extensive transverse myelitis as the sole presentation of neuro-Behçet's disease responding to infliximab. J Spinal Cord Med. 2012 Mar;35(2):122-4.

10 Lee HS, Kim Y, Shin HY, Choi YC, Kim SM. Spinal cord involvement in Behçet's disease. Mult Scler. 2016 Jun;22(7):960-3.

11 Pipitone N, Olivieri I, Padula A, D’angelo S, Nigro A, Zuccoli G, et al. Infliximab for the treatment of NeuroBehçet's disease: a case series and review of the literature. Arthritis Rheum. 2008 Feb;59(2):285-90.

12 Kuroda R, Suzuki J, Muramatsu M, Tasaki A, Yano M, Imai N, et al. Efficacy of infliximab in neuro-Behçet's disease presenting with isolated longitudinally extensive transverse myelitis. J Neurol. 2013 Dec;260(12):3167-70.

13 Uygunoğlu U, Pasha M, Saip S, Siva A. Recurrent longitudinal extensive transverse myelitis in a neuro-Behçet syndrome treated with infliximab. J Spinal Cord Med. 2015 Jan;38(1):111-4.

14 Zeydan B, Uygunoglu U, Saip S, Demirci ON, Seyahi E, Ugurlu S, et al. Infliximab is a plausible alternative for neurologic complications of Behçet disease. Neurol Neuroimmunol Neuroinflamm. 2016 Jul;3(5):e258.

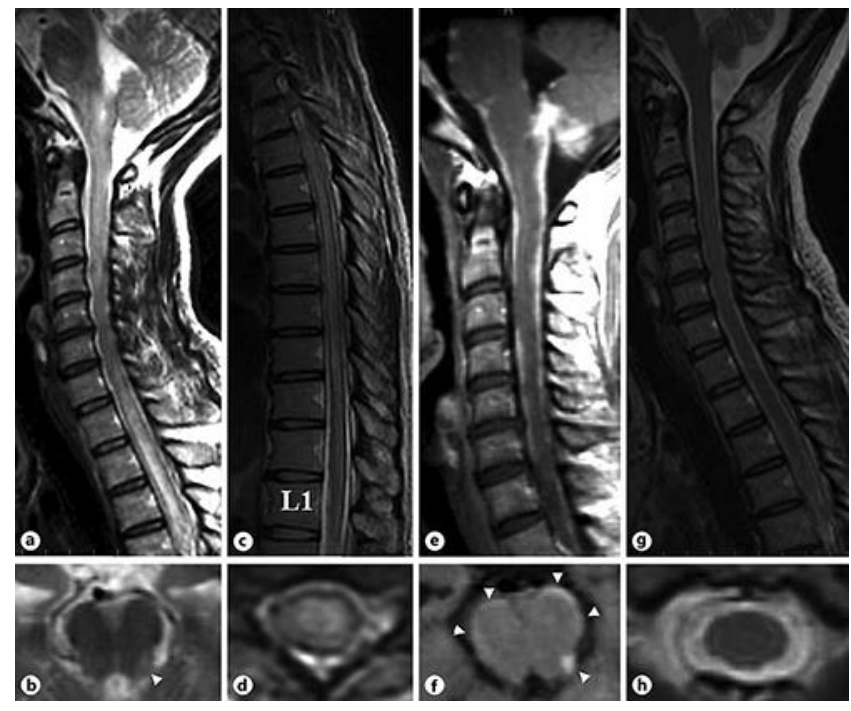

Fig. 1. Sagittal cervical and thoracic spine magnetic resonance imaging (MRI) of patient 1 on admission, showing a high-intensity lesion extending from the midbrain to L1 on T2-weighted imaging (T2WI) (a, c). Axial spine MRI showed a high signal intensity in the central part of the cord at the C2 (b, arrowhead) and Th4 level (d). Sagittal and axial contrast-enhanced T1WI showed surface enhancement of the lesions (e, $\mathbf{f}$, arrowheads). Repeat MRI showed marked regression of the brainstem and spinal lesions 35 days after admission $(\mathbf{g}, \mathbf{h})$.

\section{Karger'"}


Case Reports in Neurology
Case Rep Neurol 2021;13:78-83

DOI: $10.1159 / 000512323$

(c) www.karger.com/crn

Fujiwara et al.: Probable NBD with LETM
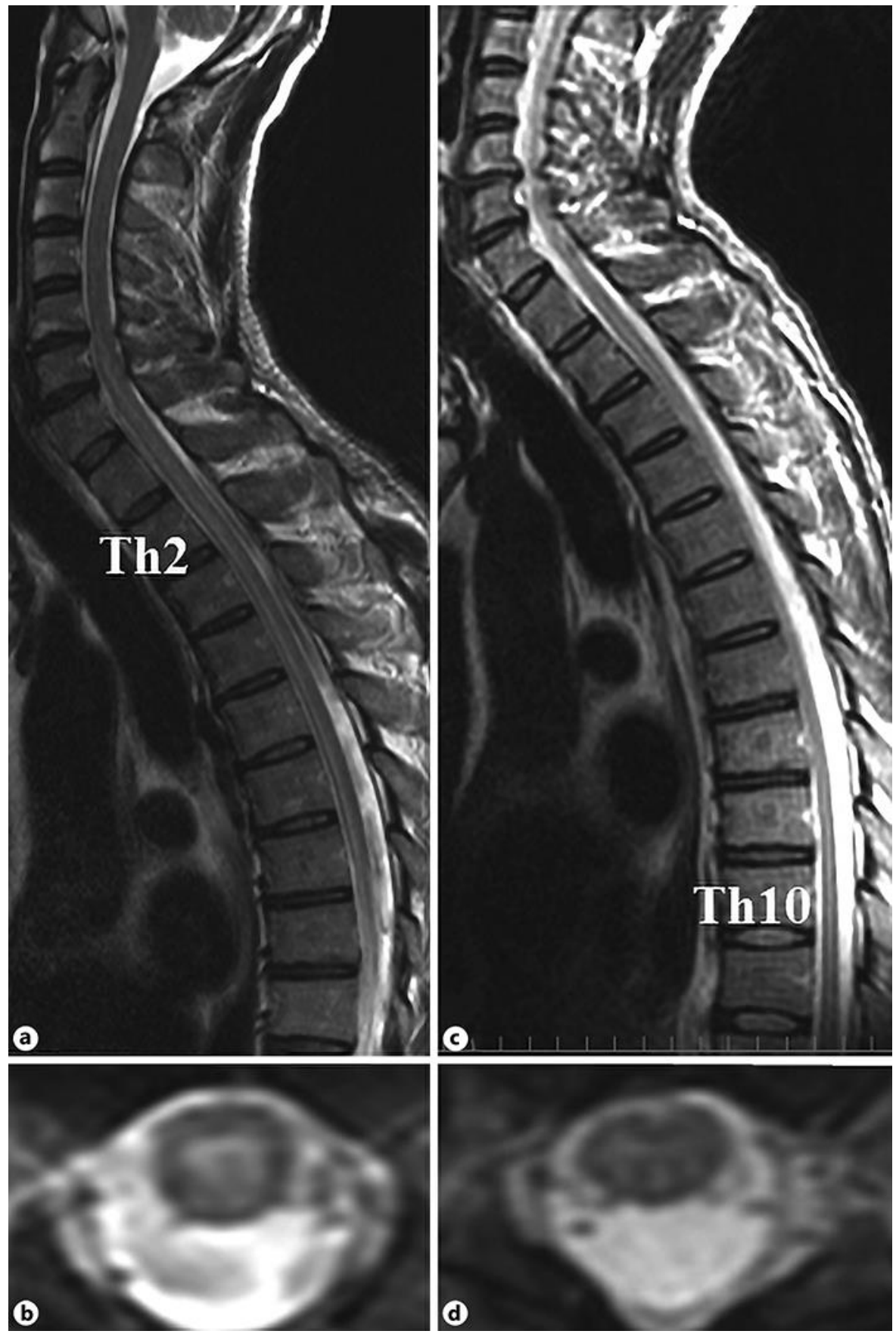

Fig. 2. Sagittal thoracic spine magnetic resonance imaging (MRI) of patient 2 on admission, showing a high signal intensity extending from Th2 to Th10 on T2-weighted imaging (T2WI) (a). Axial thoracic spine MRI showed a high signal intensity in the central part of the cord at the Th7 level (b). Repeat MRI showed marked regression of the thoracic lesion 29 days after onset (c, d). 